\title{
Laju Oksidasi Titanium Murni (Cpti Grade Tipe 340) Berlapis Hydroxyapatite (Ha) Yang Disinter Dalam Tungku Perlakuan Panas
}

\author{
Desmarita Leni ${ }^{a}$, Gunawarman ${ }^{b}$, Jon Affi $^{b}$, Yuli Yetri $^{c}$ \\ ${ }^{a}$ Sekolah Menengah Kejuruan Semen Padang \\ ${ }^{b}$ Jurusan Teknik Mesin, Fakultas Teknik, Universitas Andalas, Kampus Limau Manis, Padang, 25163 \\ ${ }^{c} J u r u s a n$ Teknik Mesin, Politeknik Negri Padang, Indonesia
}

INFORMASI ARTIKEL

Sejarah Artikel:

Diterima Redaksi: 08 Februari 2019

Revisi Akhir: 22 Maret 2019

Diterbitkan Online: 29 April 2019

\begin{tabular}{l} 
KATA KUNCI \\
\hline Hydroxyapatite \\
Comercial Pure Titanium \\
Weight Loss \\
Sintering. \\
KORESPONDENSI
\end{tabular}

E-mail: desmaritaleni@gmail.com yuliyetri@pnp.ac.id

\section{PENDAHULUAN}

Ilmu material saat ini berkembang dengan sangat pesat, salah satu aplikasinya adalah bidang biomaterial. Biomaterial yang ideal adalah bahan atau material yang memiliki biokompatibilitas yang baik, sifat mekanik yang baik dan proses manufaktur yang mudah [1]. Bahasan menarik dalam hal biomaterial adalah implantasi. Implan digunakan dengan berbagai alasan antara lain sebagai pengganti jaringan yang rusak disebabkan oleh penyakit maupun trauma, sebagai filler dan support fase penyembuhan.
Biokompatibilitas secara terminologi menjelaskan kondisi dimana tidak terjadi interaksi berbahaya antara material asing dengan tubuh. Biokompatibilitas merupakan sistem yang mencakup fisik, kimia, biologis, medik dan aspek desain [2]. Ductility, thoughness, creep dan wear resistance adalah sifat mekanik yang diperlukan untuk biomaterial, sedangkan metode fabrikasi, konsistensi, tingkat kenyamanan dan biaya produksi adalah karakter manufaktur yang pada akhirnya menentukan pemilihan penggunaan bahan implan [1]. 
Karakteristik Unalloyed Comercial Pure (CP) titanium tersedia empat kelas yang berbeda, yaitu 1, 2, 3 dan 4, yang digunakan berdasarkan ketahanan korosi. Titanium grade 2 lebih kuat dari grade 1 dan tahan korosi sangat baik, serta kemampuan dan kekuatan antara nilai grade 1 dan 3. Grade 2 ini yang banyak digunakan, yang menawarkan kekuatan hasil minimal $275 \mathrm{MPa}$ (40ksi). Titanium (CPTi grade 2) untuk aplikasi medis sering digunakan untuk bahan implan tulang, gigi, pelapisan permukaan (surface coating). Pada saat ini CPTi dipakai pula untuk bahan mahkota tiruan, gigi tiruan sebagian, gigi tiruan penuh dan untuk bahan wire kawat orthodontic.

Dengan bentuk dan sifatnya yang menguntungkan, titanium mampu menghasilkan intimate contact dengan jaringan tulang yang baru terbentuk. Hal ini memberikan stabilitas dan keberhasilan implantasi permanen bagi jaringan tubuh. Namun dilihat dari sisi bioaktifitas atau kemampuan penyatuan jaringan masih kurang [4].

Bioaktifitas titanium ini bisa ditingkatkan dengan melapisi permukaan titanium dengan bahan bioaktif seperti hydroxyapatite (HA). Disamping meningkatkan bioaktifitas, pelapisan HA diharapkan meningkatkan ketahanan korosinya. Oleh sebab itu penelitian ini difokuskan kepada pengaruh pelapisan hydroxyapatite (HA) terhadap laju korosi yang diukur dengan cara mengekspos titanium berlapis titanium murni di dalam tungku terbuka pada saat proses sintering. Melalui proses ini lapisan HA diharapkan dapat untuk pengganti penggunaan tungku vakum selama proses sintering.

\section{TINJAUAN PUSTAKA}

\subsection{Titanium}

Titanium merupakan salah satu unsur kimia dalam tabel periodik yang memiliki simbol Ti dengan nomor atom 22. Unsur ini merupakan logam transisi yang memiliki karakteristik ringan, kuat, berkilau, tahan korosi (termasuk tahan terhadap air laut dan klorin) dengan warna putih-metalikkeperakan. Unsur titanium ditemukan oleh Reverend William Gregor pada tahun 1790, dan pada tahun 1910 bentuk pure titanium pertama kali diproduksi [4].

Ada dua sifat penting sebagai dasar pemanfaatan titanium, yaitu ketahanan korosi dan rasio kekuatan terhadap densitas yang paling tinggi di antara semua logam [5]. Titanium dapat digunakan sebagai alloy melalui penambahan unsur logam lainnya seperti besi, aluminium, vanadium, dan molybdenum sehingga diperoleh material alloy dengan sifat mekanis yang kuat namun ringan. Material titanium dapat diaplikasikan pada beberapa aspek seperti penerbangan (mesin jet, misil, dll), militer, proses industri (kimia dan petrokimia, pabrik desalinasi, pulp, dan kertas), otomotif, agro industri, alat kedokteran, implan ortopedi, peralatan dan instrumen dokter gigi, implan gigi, alat olahraga, perhiasan, telepon genggam, dan aplikasi lainnya [6].

\section{Sifat Mekanik Titanium CPTi Grade 2}

Titanium (Ti) telah menjadi material pilihan untuk banyak digunakan dalam implantasi gigi dan bedah tulang. Hal tersebut dikarenakan minimalnya reaksi jaringan yang diakibatkan oleh penanaman material ini dalam tubuh. Pada penanaman material ini terjadi reaksi biologis secara alami yaitu terbentuknya jaringan baru yang kemudian melekat pada lapisan oksida pada permukaan titanium.

Tabel 1. Sifat Mekanik Titanium

\begin{tabular}{|l|c|c|c|c|}
\hline \multicolumn{1}{|c|}{$\begin{array}{c}\text { Sifat } \\
\text { Mekanik }\end{array}$} & Grade 1 & Grade 2 & Grade 3 & Grade 4 \\
\hline $\begin{array}{l}\text { Tensile } \\
\text { Strenght } \\
\text { (Mpa) }\end{array}$ & 240 & 345 & 450 & 550 \\
\hline $\begin{array}{l}\text { Yield } \\
\text { Strength } \\
\text { (Mpa) }\end{array}$ & 170 & 275 & 380 & 485 \\
\hline $\begin{array}{l}\text { Elongation } \\
\text { (\%) }\end{array}$ & 24 & 20 & 18 & 15 \\
\hline $\begin{array}{l}\text { Reduction of } \\
\text { Area (\%) }\end{array}$ & 30 & 30 & 30 & 25 \\
\hline $\begin{array}{l}\text { Modulus of } \\
\begin{array}{l}\text { Elasticity } \\
\text { (Gpa) }\end{array}\end{array} \quad 102$ & 102 & 103 & 104 \\
\hline Poison ratio & 0,34 & 0,34 & 0,34 & 0,34 \\
\hline Condition & Annealed & Annealed & Annealed & Annealed \\
\hline (Wt \%) Ti & 99,5 & 99,2 & 99,1 & 99,0 \\
\hline
\end{tabular}

Titanium (CPTi grade 2) merupakan material allotropik dengan dua bentuk kristalografi yaitu alpha $(\alpha)$ yang mempunyai bentuk hexagonal close packed $(\mathrm{HCP})$ pada temperatur $<882,5^{\circ} \mathrm{C}$ dan beta ( $\beta$ ) dengan bentuk body centered cubic (BCC) pada temperatur $>882,5^{\circ} \mathrm{C}$.

\subsection{Hydroxyapatite (HA)}

Hydroxyapatite (HA) dengan rumus kimia $\mathrm{Ca}_{10}\left(\mathrm{PO}_{4}\right)_{6}(\mathrm{OH})_{2}$ sering dikenal sebagai calcium phosphate tribasic. Selama hampir 2 dekade ini banyak mendapat perhatian di dunia biomaterial sebagai material implan dikarenakan sifat 
bikompabilitasnya yang sangat baik. HA juga merupakan merupakan material yang bersifat bioaktif disebabkan karena rasio kalsium-fosfat pada material ini mirip dengan tulang dan gigi alami.

\subsection{Elektroforesis Deposisi (EPD)}

Elektroforesis Deposisi (EPD) merupakan suatu teknik yang menggunakan mekanisme elektroforesis untuk menggerakkan partikel bermuatan dalam larutan atau suspensi karena adanya pengaruh medan listrik, sehingga partikel tersebut akan mengendap pada permukaan suatu substrat dan membentuk lapisan tipis dengan ketebalan tertentu. Metode EPD dapat digunakan untuk melapiskan material logam yang bertujuan diantaranya meningkatkan biokompatibilitas dari logam sehingga aman digunakan di dalam tubuh makhluk hidup.

\subsection{Metode Kehilangan Berat (Weight Loss)}

Metode Weight Loss merupakan salah satu metode yang dilakukan untuk mengukur laju korosi. Metode kehilangan berat dilakukan dengan cara menimbang berat awal sampel, dan setelah dilakukannya perendaman, dilakukan penimbangan kembali pada sampel. Didapatkan besarnya berat yang hilang yang nantinya digunakan pada perhitungan laju korosi. Laju korosi didapatkan melalui persamaan berikut:

Laju Korosi $=\frac{K x W}{D x A x T}$

Keterangan:

$$
\begin{aligned}
\mathrm{K} & =\text { konstanta } \\
\mathrm{W} & =\text { berat yang hilang }(\mathrm{g}) \\
\mathrm{D} & =\text { density benda uji korosi }\left(\mathrm{g} / \mathrm{cm}^{3}\right) \\
\mathrm{A} & =\text { luas permukaan }\left(\mathrm{cm}^{2}\right) \\
\mathrm{T} & =\text { waktu }(\mathrm{jam})
\end{aligned}
$$

\section{METODE PENELITIAN}

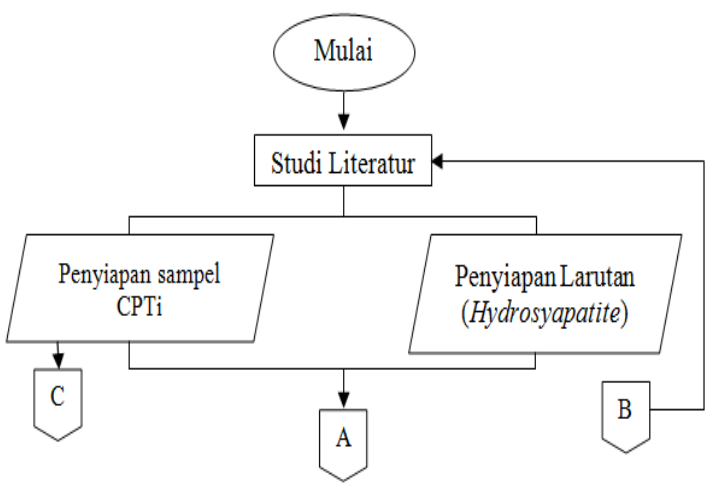

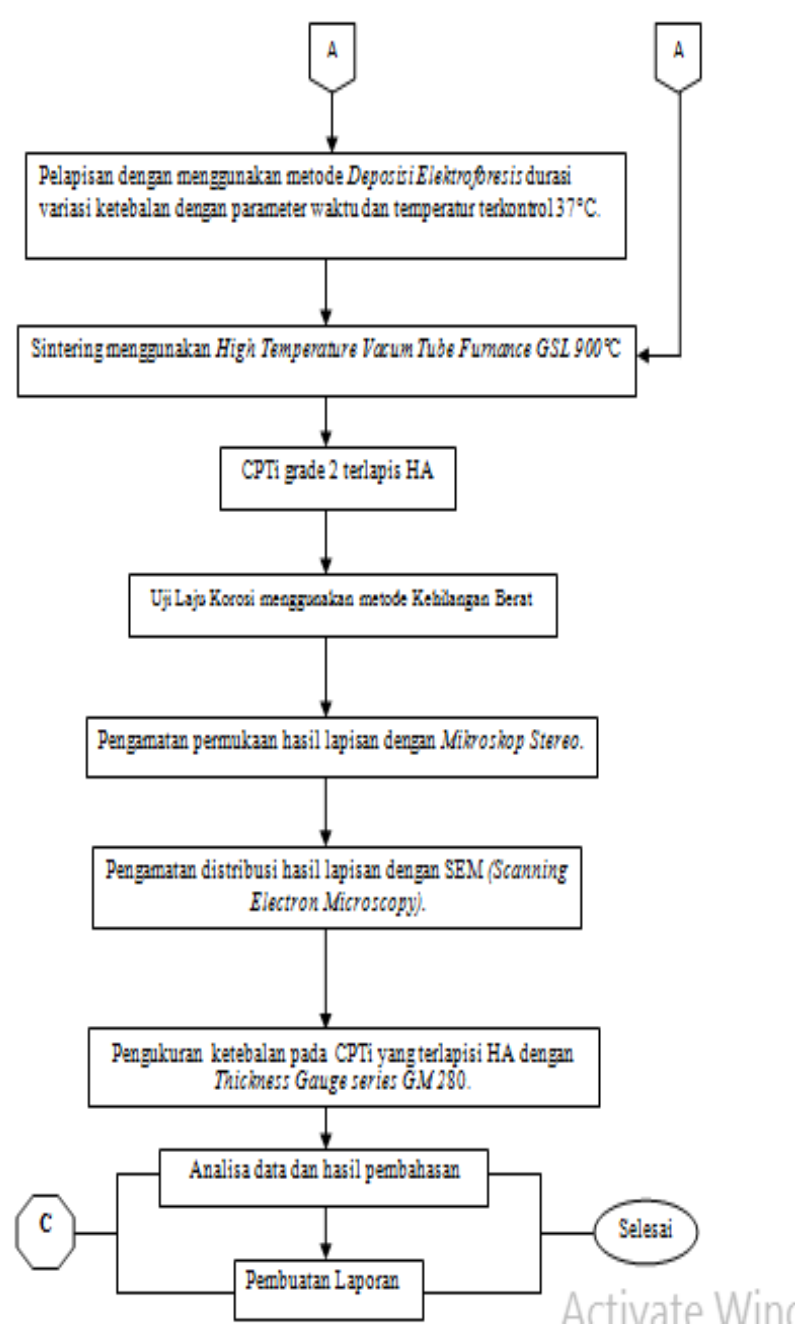

Gambar 1. Skema Penelitian

Penelitian ini dimulai dengan studi literatur dengan tujuan memahami teori-teori yang berhubungan dengan penelitian. Kemudian mempersiapkan benda uji (memotong benda uji sesuai dengan dimensi yang ditetapkan, mengetsa serta melakukan pemeriksaan struktur mikro). Selanjutnya dilakukan pengujian perilaku korosi terhadap material benda uji pada lingkungan CPTi yang terlapisi HA. Setelah semua tahapan di atas selesai, maka dilakukan analisa dan pembahasan terhadap hasil pengujian. Kemudian baru diambil kesimpulan terhadap penelitian uji korosi dengan metode weight loss pada benda uji CPTi yang sudah terlapisi HA. Alur kerja dari penelitian ini dapat dilihat pada Gambar 1.

\section{HASIL DAN PEMBAHASAN}

Hasil lapisan hydroxyapatite yang terbentuk setelah proses pelapisan menggunakan metode Electrophoretic Deposition pada permukaan 
seperti terlihat pada Gambar 2, dan tebal lapisan setelah disintering disajikan pada Tabel 2.

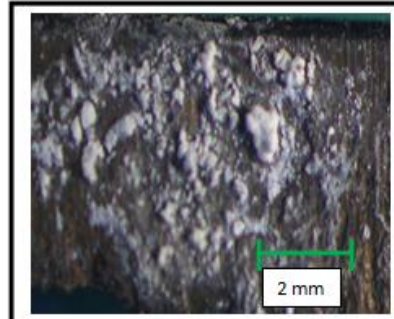

(a)

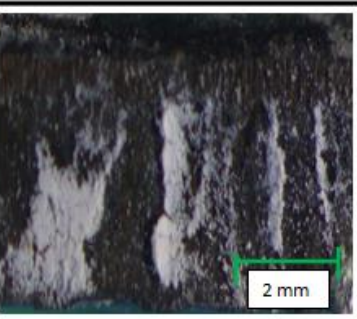

(b)

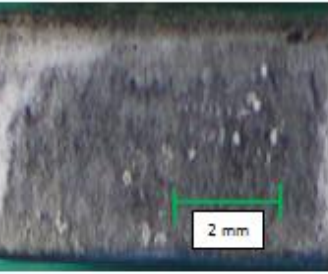

(c)

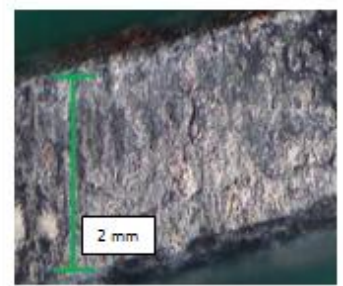

(e)

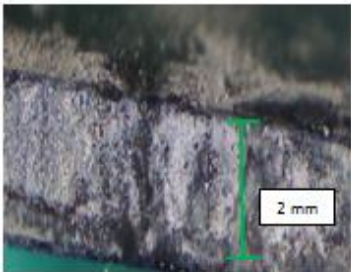

(d)

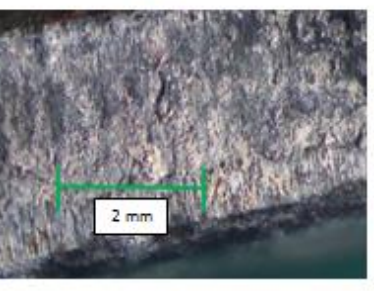

(f)
Gambar 2. Hasil pengamatan penampang dengan Mikroskop optik Olympus SZX10 permukaan hasil pelapisan dengan metode EPD pada benda uji
a) $\mathrm{CPTi} \mathrm{T}=5$ menit
b) $\mathrm{CPTi} \mathrm{T}=10$ menit
c) $\mathrm{CPTi} \mathrm{T}=15$ menit
d) $\mathrm{CPTi} \mathrm{T}=20$ menit
e) $\mathrm{CPTi} \mathrm{T}=25$ menit
f) $\mathrm{CPTi} \mathrm{T}=30$ menit
g) $\mathrm{CPTi} \mathrm{T}=35$ menit.

Tabel 2. Tebal lapisan $(\mu \mathrm{m})$ HA pada permukaanCPTi setelah sintering

\begin{tabular}{|c|c|c|c|c|c|}
\hline No & $\begin{array}{c}\text { Waktu } \\
(\mathbf{m e n i t})\end{array}$ & $\begin{array}{c}\text { Tebal } \\
\text { Lapisan } \\
(\boldsymbol{\mu m}) \\
\mathbf{U j j i} \mathbf{1}\end{array}$ & $\begin{array}{c}\text { Tebal } \\
\text { Lapisan } \\
(\boldsymbol{\mu m}) \\
\mathbf{U j j i} 2\end{array}$ & $\begin{array}{c}\text { Tebal } \\
\text { Lapisan } \\
(\boldsymbol{\mu m}) \\
\mathbf{U j j i} 3\end{array}$ & $\begin{array}{c}\text { Rata }- \\
\text { Rata } \\
(\boldsymbol{\mu m})\end{array}$ \\
\hline 1 & 5 & 24,80 & 24,79 & 24,81 & 24,80 \\
\hline 2 & 10 & 28,50 & 28,52 & 29,12 & 28,71 \\
\hline 3 & 15 & 28,90 & 28,88 & 29,01 & 28,93 \\
\hline 4 & 20 & 30,00 & 31,25 & 30,89 & 30,71 \\
\hline 5 & 25 & 30,20 & 30,43 & 29,98 & 30,20 \\
\hline 6 & 30 & 32,00 & 32,50 & 31,92 & 32,14 \\
\hline 7 & 35 & 32,70 & 33,65 & 34,99 & 33,78 \\
\hline
\end{tabular}

Pada Tabel 2 terlihat bahwa ketebalan lapisan HA pada permukaan CPTi merupakan rata-rata dari $3 \mathrm{x}$ perlakuan. Dari Tabel 2 dan Gambar 3 terlihat bahwa tebal lapisan HA yang terbentuk di permukaan CPTi berbanding lurus dengan waktu pelapisan. Hal ini dapat dilihat dari persamaan garis lurus yang diperoleh pada Gambar 3 .

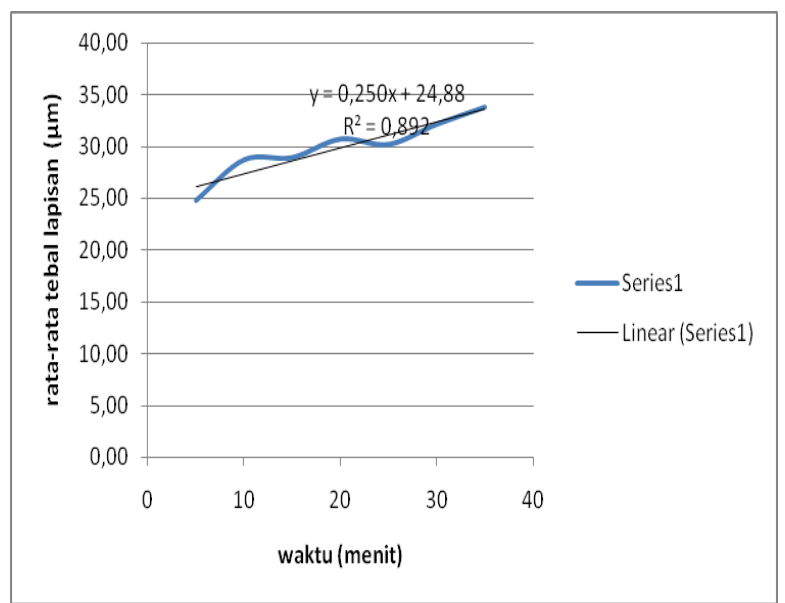

Gambar 3. Grafik Tebal lapisan HA sebagai fungsi waktu

Gambar 3 membuktikan semakin lama waktu pelapisan benda uji CPTi semakin tebal lapisan HA yang didapatkan. Pengujian antara waktu EPD dan ketebalan lapisan adalah linear dengan persamaan $\mathrm{Y}=0,250 \mathrm{X}+24,88$ dan $\mathrm{R}^{2}=0,892$ linear terhadap sumbu $\mathrm{X}$. Peningkatan ketebalan lapisan terhadap waktu terjadi karena analisa besar daya melekatnya larutan pada permukaan titanium. Hasil pengujian laju korosi pada benda uji CPTi setelah disintering dihitung dengan metode kehilangan berat (Weight Loss). Kehilangan massa yang terjadi selama proses pengujian dan laju korosinya dapat pada Tabel 3.

Tabel 3. Hasil laju korosi CPTi

\begin{tabular}{|c|c|c|c|c|c|c|}
\hline No & $\begin{array}{c}\text { Waktu } \\
\text { (menit) }\end{array}$ & $\begin{array}{c}\text { Volt } \\
(\mathbf{A})\end{array}$ & $\begin{array}{c}\text { W1 } \\
\text { (g) }\end{array}$ & $\mathbf{w 2}$ (g) & $\begin{array}{c}\text { Kehilangan } \\
\text { Berat (g) }\end{array}$ & $\begin{array}{c}\text { Laju } \\
\text { Korosi } \\
\text { (mm/year) }\end{array}$ \\
\hline 1 & 5 & 40 & 0,875 & 0,858 & 0,017 & 0,149 \\
\hline 2 & 10 & 40 & 0,879 & 0,873 & 0,006 & 0,026 \\
\hline 3 & 15 & 40 & 0,852 & 0,842 & 0,010 & 0,030 \\
\hline 4 & 20 & 40 & 0,859 & 0,848 & 0,011 & 0,024 \\
\hline 5 & 25 & 40 & 0,856 & 0,848 & 0,008 & 0,014 \\
\hline 6 & 30 & 40 & 0,853 & 0,844 & 0,009 & 0,013 \\
\hline 7 & 35 & 40 & 0,865 & 0,855 & 0,010 & 0,013 \\
\hline
\end{tabular}

Terjadinya korosi pada titanium murni sewaktu pengujian mungkin akibat dari saat sintering 
tungku terbuka, sehingga saat pendinginan yang berlangsung selam 24 jam dipengaruhi oleh lingkungan sekitarnya salah satunya oksigen. Untuk pembuktian bahwa pengujian yang dilakukan masih dalam standar ketahanan korosi relatif dapat dilihat pada resistance corosion engineering pada Tabel 4. Dari hasil analisa pengujian ketahanan korosi relative, ternyata benda uji CPTi memiliki resistance Exellent yang berkisar antara 0,02-0,1 mm/year seperti yang ditunjukkan pada Tabel 4.

Tabel 4. Ketahanan korosi relatif

\begin{tabular}{|l|c|c|c|c|c|}
\hline Resistance & $\mathbf{m p y}$ & $\begin{array}{c}\mathbf{m m} / \\
\mathbf{y e a r}\end{array}$ & $\begin{array}{c}(\boldsymbol{\mu m}) / \\
\text { year }\end{array}$ & $\mathbf{N m} / \mathbf{h}$ & $\mathbf{P m} / \mathbf{s}$ \\
\hline Outstanding & $<1$ & $<0,02$ & $<25$ & $<2$ & $<1$ \\
\hline Exellent & $1-5$ & $\begin{array}{c}0,02- \\
0,1\end{array}$ & $25-100$ & $2-10$ & $1-5$ \\
\hline Good & $5-20$ & $0,1-0,5$ & $100-500$ & $10-50$ & $20-50$ \\
\hline Fair & $20-50$ & $0,5-1$ & $500-1000$ & $50-150$ & $20-50$ \\
\hline Poor & $50-$ & $1-5$ & $1000-$ & $150-$ & $50-200$ \\
& 200 & & 5000 & 500 & \\
\hline Unacuptable & $200+$ & $5+$ & $5000+$ & $500+$ & $200+$ \\
\hline
\end{tabular}

Hasil analisa ketahanan korosi CPTi tersebut menunjukan bahwa kualitas titanium murni tidak terdegrasi akibat korosi karena laju korosi yang didapatkan rata-rata tergolong Exellent dan masih dalam batas korosi relatif. Pernyataan ini didukung oleh hasil pengamantan pada Gambar 4.

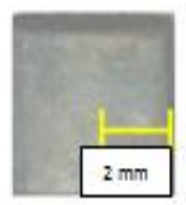

(a)

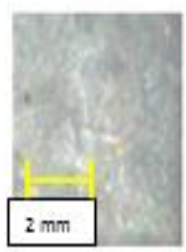

(e)

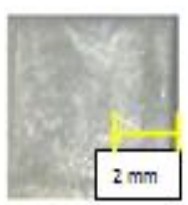

(b)

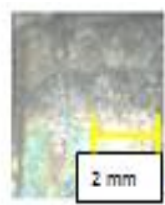

(c)

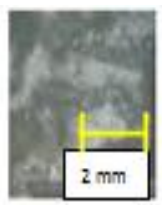

(d)

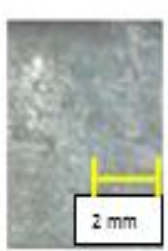

(f)

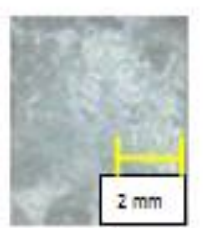

(g)
Gambar 4. Permukaan CPTi yang sudah dibersihakan dari lapisan HA dilihat dengan Mikroskop optik Olympus SZX10 dengan skala $2 x$ perbesaran.

a) Permukaan CPTi yang dilapisi HA T $=5$ menit

b) Permukaan CPTi yang dilapisi HA T $=10$ menit

c) Permukaan CPTi yang dilapisi HA T $=15$ menit

d) Permukaan CPTi yang dilapisi HA T $=20$ menit

e) Permukaan CPTi yang dilapisi HA T $=25$ menit

f) Permukaan CPTi yang dilapisi HA T $=30$ menit

g) Permukaan CPTi yang dilapisi HA $\mathrm{T}=35$ menit.
Dari Gambar 4 menunjukkan semakin tebal lapisan HA yang melapisi titanium murni maka semakin terlindungi permukaannya dari korosi pada saat disinter dalam tungku terbuka.

\section{KESIMPULAN DAN SARAN}

Berdasarkan hasil penelitian yang telah dilakukan, beberapa kesimpulan:

1. Ketebalan lapisan yang terbentuk di permukaan titanium murni (CPTi grade 2) berbanding lurus waktu EPD, dimana semakin lama waktu pelapisan maka semakin tebal lapisan HA yang didapatkan.

2. Semakin tebal lapisan yang terbentuk pada permukaan titanium murni (CPTi) maka semakin kecil laju korosi yang terjadi.

3. Ketahanan korosi pada CPTi tidak menyebabkan kualitas titanium murni terdegradasi akibat korosi, karena hasil laju korosi yang didapatkan rata- rata Exellent dan masih dalam batas relatif ketahanan korosi untuk implan.

\section{UCAPAN TERIMA KASIH}

Terimakasih kepada YISP dan Kepala Sekolah SMK Semen Padang yang sudah memberikan izin dan suport moril untuk melanjut dan menyelesaikan studi S2 di Jurusan Teknik Mesin, Fakultas Teknik, Universitas Andalas, Padang.

\section{DAFTAR PUSTAKA}

[1] Karokaro, M., Purniawan, A., Fellicia, D.M., 2008, Karakterisasi Lapisan Pasif Korosi Impant Commersial Pure Titanium Grade 2 Dengan Variasi Kekasaran Permukaan Pada Cairan Tubuh Buatan, Jurnal Ilmiah Sains dan Teknologi Vol. 7 No. 2, 97-105.

[2] Spenser Nicholas D, Texor Marcus, 1998, Surface Modification, Surface Analysis and Biomaterials, Material Science, ETH-Zurich.

[3] Bombac D, Brojan, M, Krkovic, M., Turk, R., Zalar, A., 2001, Characterization of Titanium and Stainless Steel Medical Implants Surfaces. Materials and Geoenvironment, Vol. 54, 151-164.

[4] The International Programme on Chemical Safety (IPCS). Titanium. Geneva: World Health Organization. 1982; p. 14-49.

[5] Donachie, Matthew J, Jr. (1988). TITANIUM: A Technical Guide. Metals Park, OH: ASM International. p. 11. 